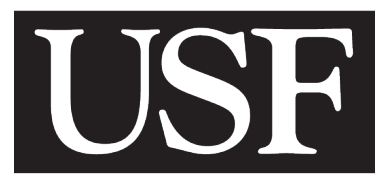

Muma Case Review

A publication of the Muma College of Business | University of South Florida

\begin{tabular}{llrrr}
\hline Volume 4 & Number 13 & 31 DEC 2019 \\
\hline JAMES FARLEY, RAJENDER & KATYAL, RISHIRAJ & MUKHERJEE, MIKE & SINGH, MEENA \\
YADUGURI SUNDINTI & &
\end{tabular}

\title{
TRANSFORMATION OF BUSINESS USING GAMIFICATION ${ }^{1}$
}

"Games are the only force in the known universe that can get people to take actions against their self-interest, in a predictable way, without using force."

Mike Joshi (MJ) - IT Director of ABC Corp (ABC) just got done with a meeting with Bob - Executive Vice President of Global Field Operations and Assurance for ABC Corp. MJ was asked to improve the output of ABC Corp's current workforce to stay competitive in the hyper competitive telecommunications sector using technology. Bob demanded that MJ figure out a way to improve efficiency in ABC's staff as they needed to push for the $5 \mathrm{G}$ deployment as well as Intelligent Edge Network. MJ was already aware of the fact that T-Mobile, one of ABC Corp's fiercest competitors, was gaining traction on them on network connectivity, customer satisfaction and plethora of services it was providing. T-Mobile was offering incentives to ABC Corp's existing customer to leave ABC Corp and move their service.

5G was in the midst of deployment and could become a game changer in terms of mobile connectivity and data throughput. It was a necessity in the world of social media, where most of the world population had handheld devices. Bob knew he needed skilled technology workers as well as customer care to support this mobile technology. How would he achieve such a goal, especially after the recent job restructuring at $\mathrm{ABC}$ Corp? Bob wanted to know how he could squeeze higher performance from his top performers in the company using technology. Could he drive someone to put in the hard work required for the implementation of $5 \mathrm{G}$ and supporting existing technology and services? Bob needed a leaner and much more agile workforce. Bob needed employees to keep moving the goal line for the performance metric since T-Mobile had been able to win over some contracts with large corporations. T-Mobile was able to offer a faster time for implementation of network services and Bob knew that to improve efficiency at $\mathrm{ABC}$ Corp he needed a cultural transformation inside the workforce.

MJ knew he did not have much time to come up with a presentable plan to management. Bob was wondering if IT could build and implement any solution to help with the cultural transformation he needed. Bob also suspected that there was an efficiency problem with the ABC Corp's task force; he knew he would need MJ to pull some reports and analyze them to make sure he could back up his gut instinct.

${ }^{1}$ Copyright (C) 2019, Group 5-James Farley, Rajender Katyal, Mike Singh, Rishiraj Mukherjee, Meena Yaduguri Sundinti. This case was prepared for the purpose of class discussion, and not to illustrate the effective or ineffective handling of an administrative situation. Names and some information have been disguised. This case is published under a Creative Commons BY-NC license. Permission is granted to copy and distribute this case for noncommercial purposes, in both printed and electronic formats. 


\section{TELECOMMUNICATION INDUSTRY}

The telecommunications industry was a sector within information and communication technology. It consisted all telecommunications/telephone companies and internet service providers. The telecommunications industry played a crucial role in the evolution of mobile communications and social networking. The industry could be visualized as the world's biggest machine linked together with complex networks, POTS, telephones, mobile phones, IOT, and internet enabled devices.

\section{Importance of Telecommunication in Business}

Telecommunication was an important tool for businesses as the Internet of Things (IoT) grew and the business world grew evermore connected. Mobile telecommunication gave companies the opportunity to introduce a more flexible working environment, for example, by allowing employees to work remotely from home. The introduction of smartphones gave employees new levels of productivity and capability on the move.

\section{Communication Network at a Glance}

The most common example of a cellular network was a mobile phone (cell phone) network. A mobile phone was a portable device that received or made calls through a cell site (base station) or transmitting tower. Radio waves were used to transfer signals to and from the cell phone.

\section{Importance of Wireless and Future Growth}

Wireless had started its next transformation wave to $5 \mathrm{G}$ and beyond. So, which parts of the wireless industry would grow? The last few decades had seen the industry change and grow. The wireless industry as a whole first shifted from analog to digital. It then shifted from $2 \mathrm{G}$ to $3 \mathrm{G}$ and then $3 \mathrm{G}$ to $4 \mathrm{G}$. The most recent major shift in wireless growth had been spurred by the introduction of the iPhone and Android smartphones using 4G, accompanied by dramatic growth in the percentage of people that used wireless phones. Over the past decade, app market had grown from a few hundred to more than two million.

Typically, when the wireless industry grew and changed, it happened in one area and every player participated equally. Going forward, economists saw wireless growing and changing in many different directions simultaneously. 5G was on the way, offering many applications beyond mobile phones. In consequence, growth was expected to look very different going forward. As all carriers prepare for this transformation to $5 \mathrm{G}$ over the next several years, networks, cell sites, and smartphones all need to be updated. That would take time and money. To be determined: which companies and which sectors would be hot and which would cool down?

\section{ABC CORP COMMUNICATIONS}

ABC Corp Communications was an American multinational telecommunications conglomerate and a corporate component of the Dow Jones Industrial headquartered in New York. In 1984, the Justice Department of the United States mandated AT\&T Corporation to break up the Bell System and split into seven companies, called "Baby Bells". One of the baby bells, Bell Atlantic came into existence in 1984 consisting of the separate operating companies New Jersey Bell, Bell of Pennsylvania, Diamond State Telephone, and C\&P Telephone, with a footprint from New Jersey to Virginia.

ABC Corp was created on June 30, 2000 by Bell Atlantic and GTE (General Telephone \& Electronics) Corps. in one of the largest mergers in U.S. history. ABC Corp has coverage in $98 \%$ of the United States and is $100 \%$ fiber-optic plus reach over 1 billion people around the world. ABC Corp had already started 
launching 5G Wi-Fi Networks that would increase speed and bandwidth for internet use while lowering latency. In 2015, ABC Corp expanded its business into content ownership by acquiring AOL, and two years later it acquired Yahoo!. AOL and Yahoo were amalgamated into a new division named Oath Inc.

\section{ABC Corp Wireless}

Cellco Partnership, Inc., doing business as ABC Corp Wireless, provided wireless communications services across wireless networks in the United States. With 154 million subscribers in Q3 2018, ABC Corp Wireless was the largest wireless telecommunications provider in the United States. ABC Corp also provided fourth-generation (4G) Long-Term Evolution (LTE) technology and third-generation (3G) Evolution-Data Optimized (EV-DO) networks. The company offered wireless services on a postpaid and prepaid basis. Retail (non-wholesale) postpaid accounts primarily consisted of retail customers under contract with ABC Corp Wireless that were directly served and managed by ABC Corp Wireless and used its branded services. The company offered various postpaid account service plans, including shared data plans, single connection plans and other plans tailored to the needs of its customers. Its shared data plans featured domestic unlimited voice minutes, unlimited domestic and international text, video and picture messaging, cloud storage and a single data allowance that could be shared among the wireless devices on a customer's account.

ABC Corp offered a range of wireless services accessible on a variety of its devices. It also offered service that enables its customers to access the Internet wirelessly at broadband speeds on notebook computers and tablets. Customers could access multimedia offerings, provided by ABC Corp and by third parties, consisting of applications providing music, video, gaming, news and other content. Its businessfocused offerings included solutions that enabled customers to access the Internet, their corporate intranets and e-mail across its diverse portfolio of wireless devices. Its location-based services provided its customers with directions and enabled its business customers to locate, monitor and communicate with their mobile field workers. Its global data services allowed its customers to access the Internet on supported smartphones, tablets and basic phones internationally.

ABC Corp provided network access and, in some cases, services to support wireless connections for the Internet of things (IoT). Its IoT services offered end-to-end solutions for various IoT vertical markets, such as fleet management and telematics, energy, agricultural technology and smart communities. It provided in-vehicle solutions that enabled vehicle navigation, global positioning system (GPS) tracking, engine diagnostic monitoring and maintenance alerts. It offered solutions that provided the energy sector with visibility into energy usage and the ability to monitor devices used to track energy usage. It provided solutions that give farmers data they needed to improve yields and save costs. ABC Corp's solutions enabled localities to collect data from IoT and connected machine technologies to improve public safety, manage traffic, reduce pollution, and identify revenue generation opportunities.

\section{ABC Corp Wireline}

ABC Corp's Wireline segment provided voice, data and video communications products and services. The company organized its service and product offerings into customer segments. These included Consumer Markets, Enterprise Solutions, Partner Solutions and Business Markets. Consumer Markets operations provided broadband services, including high-speed Internet, Fios Internet and Fios Video services, and local exchange, including basic service and end user access, and long distance, including regional toll, voice services to residential and small business subscribers. The company offered Fios Internet and highspeed Internet services with varying throughput speeds. 
The company offered video service over its fiber-optic network. It provided offerings to its Fios television customers, including Fios Quantum TV. It offered voice services that include local exchange, regional and long distance calling and voice messaging services, as well as VoIP services, which used the Internet or private broadband networks to transmit voice communications.

Enterprise Solutions provided communications services to medium and large business customers, including multinational corporations, as well as state and federal government customers. ABC Corp Enterprise Solutions services included Global Internet protocol (IP) network access, cloud and information technology (IT) solutions, business communications, IoT, data, security and mobility services. The company's networking products and solutions consisted primarily of private IP, ethernet access and optical networking services. Private IP service enabled customers across the world to communicate over a private, secure network using a range of access methods, including Ethernet and ABC Corp Wireless 4G LTE.

Partner Solutions offered communications services, including data, voice, local dial tone and broadband services primarily to local, long distance and other carriers that used the company's facilities to provide services to their customers. Partner Solution's services included data services, voice services and local services. Mobility enabled wholesale customers to enhance their portfolio to include triple-play or quadplay capability by leveraging wireless devices and services offered through ABC Corp Wireless that could be packaged and resold under their own carrier brand. Security offered wholesale customers integrated solutions to help their enterprise end users secure their networks and data. The company provided switched access services that allowed carriers to complete their end user calls that originated or terminated within its territory.

Business Markets included United States-based small business customers. Business Markets also included United States-based medium business customers, state and local government customers and educational institutions.

\section{ABC Corp Strategic product - 5G, iEN, OneFiber}

ABC Corp's Ultra-Wide Band 5G network would allow up to 100 times better throughput, 10 times longer battery life and 1,000 times larger data volumes, all while being 10 times more reliable. ABC Corp was the only company with the engineering experience, fiber assets, wireless millimeter wave spectrum and partnerships to scale the transfer of massive amounts of data at unimaginable speeds.

Along with Cisco and Juniper Networks, ABC Corp used software-defined networking (SDN) technology to combine all of its existing service edge routers for Ethernet and IP-based services onto a single platform, improving the operational efficiency of its networks while also adding increased functionality and flexibility. This new multi-service edge solution featured a disaggregated control plane and leveraged external computing resources to enhance the capabilities of that control plane beyond those of a traditional router.

Simplifying the networks' edges allowed ABC Corp to drive process improvements in the deployment and provisioning of infrastructure on its networks, as well as in customer-focused areas such as Ethernet, internet and VPN-based services. It also allowed ABC Corp to respond to technology changes in the industry more rapidly, allowing its customers to adopt changes in their technology at a much faster pace.

$\mathrm{ABC}$ Corp was deploying multimodal fiber, which would become crucial to its $\mathrm{mm}$ Wave $5 \mathrm{G}$ plans that required many fiber-fed nodes. ABC Corp's small cell 5G network architecture would require lots of 
access to gigabit-capable fiber backhaul; in urban settings, fiber backhaul would be needed at 1,000-foot intervals.

ABC Corp had previously announced fiber build-outs in 50 markets outside its incumbent local exchange carrier (ILEC) footprint. These build-outs would serve to prepare the company's networks for 5G.

"5G is an access technology. There is so much more you need to do to actually have it," Sam, the company's new CEO, said. He added that ABC Corp would soon roll out 5G fixed wireless services to consumers in Sacramento, Los Angeles and Houston. ABC Corp had promised that fixed wireless would be its first use case for $5 \mathrm{G}$.

\section{ABC Corp Voluntary Separation Program}

In parallel with its massive investment in $5 \mathrm{G}$, the $\mathrm{ABC}$ Corp was in the process of a major workforce realignment. The company had just confirmed a voluntary separation plan that was open for 46000+ employees. The plan was expected to impact about $30 \%$ of its workforce, potentially saving up to $\$ 10$ billion by 2021. A major portion of the company's IT was being outsourced to Infosys. ABC Corp's severance package mostly targeted long-time employees - those with more than 30 years at the company. With a total debt of more than $\$ 114$ billion, the carrier had limited flexibility to reach a healthy balance sheet while investing billions in capital expenditures to deploy its next-generation 5G Ultra-Wideband network and 5G broadband Internet service, and pay higher dividends to shareholders. Debt reduction, capital expenditures, dividends were the three pillars of the company's strategy under its new CEO, Sam.

\section{CURRENT CONTEXT}

Faced with the need to deploy $5 \mathrm{G}$ rapidly while simultaneously dealing with a reduced workforce, Bob knew that his options were limited. He had to come up with a solution to be able to track employees more effectively and, in the process, use technology to motivate employees. The deployment of $5 \mathrm{G}$ could not be slowed down. Bob knew he was running out of time for a potential solution to present to the CEO.

\section{The Business Challenge}

MJ knew that efficiency of engineer had always been a cause of concern, but how could he quantify that? He quickly extracted out some reports with the help of IT team and found that on an average 77 open tasks were sitting with $8+$ days of no response time from its fellow employees, meaning 77 projects were on hold as fellow contractors/employees had gone off to easier tasks or different tasks. Task SLA (service level agreement), excerpted in Exhibit 1, showed the report he used to get to this conclusion. The report also listed tasks that were on hold and number of days that tasks were on hold.

MJ did some further analysis on a separate report that showed the average time a product was being worked on, including a "qqplot" diagram of average time to work on task, shown in Exhibit 2. He noticed the data was not normal, implying that why tasks were being delayed was not easily predictable.

The manual touches performed on each task (see Exhibit 3 for a sample), listed the number of times someone worked on a system installation. On a perfect world someone would touch it once meaning they would install it and move on. Anywhere the number of touches was more implied a problem area.

The performance and work velocity report (illustrated in Exhibit 4), showed the amount of work time spent on each task. Looking at the data by region, Bob had found some serious concerns. New York City 
(NYC) and New York State (NYS) were big offenders. He found many examples (not shown) where a user could have finished a task on average 30 mins but logged $4 \mathrm{hrs}$. All of this was leading to one theme: the staff was underperforming and costing the company time and money. Bob also noticed some users were using previous versions of the proprietary $\mathrm{ABC}$ system used for installing equipment rather than the latest version and this was something Bob had to help change fast with the $5 \mathrm{G}$ push coming. This concern of Bob's pointed to a training and management issue. Bob needed his managers to train his staff better. So, did Bob need to retrain his manager?

\section{Diverse Business Units}

Compounding the challenge that Bob faced was the very different nature of the business units he supervised. Bob had 2 VP's that reported to him:

- Felicia, the Vice President of Wireline Global Operations, led wholesale \& enterprise service delivery $\&$ assurance across more than 2,600 cities in 145 countries. She also led the operation of all ABC Corp wireline network technical facilities across the globe. Her team included ABC Corp onshore \& offshore provisioning centers along with field forces supporting customer installation \& maintenance, global mesh, transport and data networks. Her organization's workforce was young and their compensation was directly linked with met or missed SLA.

- Maureen, Vice President Work Center Operations for ABC Corp Wireline Network Operations was responsible for all provisioning and maintenance activities, along with all field and central office dispatches for consumer, business, wholesale and enterprise customers. Her centers provide end-to-end installation, repair and dispatch for all voice and data services for $\mathrm{ABC}$ Corp's wholesale and enterprise customers, as well as dispatch for all of the company's consumer wireline services - core voice, HSI and FIOS. Her organization's workforce was aging with many being eligible for voluntary separation. That lead to twin challenges: willingness to change to new culture and knowledge base erosion owing to attrition.

Any solution proposed by MJ would have to work with these 2 very different workforce cultures - one adaptable and one much less so. What could IT do with this conundrum?

\section{Solution and Strategy}

After meeting with Bob, the MJ knew he was faced with a challenge where existing solutions and architecture stack might not help. With a staff of over 7000 in India that managed the majority of the data center and IT infrastructure, the new layoff meant over 3000+ of those jobs would move over to Infosys. Whatever solution he came up with would need to be done with fewer and potentially less motivated IT staff from India and on site.

MJ knew he needed to think out of the box and look outside the ABC IT organization to come up with a solution. He made a request for quote (RFQ) from different software vendors to come up with an IT solution to track employees and also help self-motivate them. After reviewing several bids $\mathrm{ABC}$ chose SCI to address the problem. SCI interviewed ABC employees on site from different regions for months. Based on interview results, SCI determined gamification (Exhibit 9-10 - gamification data) could not only improve efficiency but also help self-motivate its employees.

After being briefed by SCI design team about gamification MJ knew he had to understand more about gamification. He had read a few articles on this but implementing this in house and effectively deploying this to its employees would be a challenge. Also, this idea could be quashed by Bob who might need a 
board approval for using gamification. He also knew about obscure game play, or meaningless badge associations might cause strategic failure with the gamification project.

One aspect working in favor of the approach was the company's experience. Over the course of the previous decade, ABC Corp had launched various campaigns employing gamification - using the technique as a means of incentivizing customers to use their products through engaging users. Each campaign had different carrots intended to attract/retain customers. MJ knew the gamification notion was embedded deep inside the company. He hoped this would mean that selling the gamification idea might not be that difficult.

\section{Technology Innovation inside ABC IT}

ABC like other companies from the 2000's had experienced a problem of having deprecated under interface (UI) working with older systems. Users are often forced to use these older UI based systems and made mistakes or lost out on efficiency. MJ along with Bob had been a driving force in technology innovation inside of $\mathrm{ABC}$. ABC had 10000+ Network engineers working in 50+ locations around the world. These highly skilled workers needed a better UI and software stack to get their work done. Bob and MJ with their vision developed a Network Single Pane of Glass (NSPOG) UI to help drive innovation in custom desktop apps with simplified workflow and with machine intelligence (MI) and artificial intelligence (AI) built into them. This helped $\mathrm{ABC}$ employees with a 50\% reduction in clicks, and a $60 \%$ improvement in time on task. Many of their tasks were auto completed by AI and MI. Delivery of ABC strategic products ELINE, SES, LCI, and Intelligence Edge Network was greatly simplified with the innovation of NSPOG.

\section{GAMIFICATION}

Based on the presentations and briefings he got from SCI, MJ learned that gamification was a technique aimed at increasing users' positive motivation towards given activities. In doing so, it attempted to address a serious workforce problem. Gallup's 2016 The Worldwide Employee Engagement Crisis report found that only 32 percent of US workers were engaged with their jobs daily; less than half that number, 13 percent, were engaged worldwide. With such astounding news, companies needed to create new methods for making work more engaging. Disengaged employees were less productive and had lower morale because they tended to think negatively about their jobs. In addition, disengaged employees tended to bring their colleagues and teammates down with them, affecting the overall employee culture and spreading discontent throughout the company (Technology Advice Gamification Software Buyer's Guide, 2018).

\section{What is Gamification?}

Gamification as a process takes something that already exists - a website, an enterprise application, an online community - and integrates game mechanics into it to motivate participation, engagement, and loyalty. Gamification takes the data-driven techniques that game designers used to engage players, applying them to non-game experiences to motivate actions. When people hear about gamification, they visualize games made for a business purpose. Gamification was not about creating something new, it was about amplifying the effect of an existing, core experience by applying the motivational techniques that make games appealing. When an organization gamifies interactions with customers, employees, and partners, the organization may be able to drive more sales, create stronger collaboration, increase ROI, create deeper loyalty, produce higher customer satisfaction and more. 
Gamification had the potential to transform business models by creating new ways to extend relationships, craft longer-term engagement, and drive customer and employee loyalty. Gamification worked because it leveraged the motivations and desires that exist in all of us for community, feedback, achievement and reward. When combined with the latest research on motivation and the big data generated by user interactions, gamification could empower businesses to create true loyalty.

The components of a game were called game mechanics. Mechanics were applied to gamification by identifying and applying the right set of game mechanics to engage or motivate the user. Gamification delivered proven and tangible results, which could be measured with the analytical tools most vendors provide.

\section{Gamification in Telecommunications}

In 2013 a competitor telecommunication company (XYZ), implemented a gamification environment from Bunchball to motivate employees to adopt the new platform as part of the initiative to continuously improve service. In the new, gamified community, XYZ-Community members earned points and badges for searching the knowledgebase for answers, posting or answering questions, and rating answers as helpful ("likes"). A leaderboard also allowed each member to compare their progress with that of their peers. XYZ-Community specifically motivated members to solve problems and collaborate on a peer-topeer basis. XYZ saw support costs decrease as the community self-governed, making it more resonant and valuable to its members.

\section{Challenges of Gamification}

MJ also learned that the gamification framework in the enterprise application environment is complex. Factors contributing to that complexity included:

- Identifying sources of innovative games was difficult.

- Detailed motivational information system design required deep understanding of motivational psychology.

- Games could affect behavior in unexpected ways, adding another source of complexity to game design.

\section{GAMIFICATION Implementation Strategy}

After doing his initial research on gamification, MJ met with his Tech leads and SCI design team to chalk out a roadmap needed to implement gamification inside $\mathrm{ABC}$. MJ also invited his legal team to make sure the implementation followed contractual obligation to its employees and union workers.

MJ from the meeting understood he needed a six-step process to implement gamification:

1. MJ consulted with business and Tier-1 teams on gamification templates and he broke down project preparation into 5 broader activities.

- Identification of problem

- Identify Goals and Objective

- Add Badge/Rank to the objective

- Assess if Game is applicable 
- Identify game data-point and collection strategy.

2. MJ understood he needed to analyze the context and align it with the users.

- Function involved

- Integration with available platform

- Package and libraries requirement

- Gamification platform architecture and Algorithm

- Constraints on user and data-points

Context Analysis: Once the context was identified he passed it to various business supervisors to ensure that they were in-line with our context analysis. Once context attributes were understood, he defined success metrics without business point of contact.

User analysis

- Identification of sample and population of the user to onboard to gamification platform.

- Designed Game and mechanics to cater to user requirements.

- All engineers' motivations were identified.

- Avatar creation based on user profile.

3. MJ knew he had to also design gamification algorithm and template.

- Task Volume: Number of tasks completed within a given timeframe

- Task Volume (alt): Number of tasks received AND completed within a given timeframe.

- Task Time: Number of tasks completed within 'target' time

- SLA Met: (Positive frame) number of Orders/SRs that meet a target delivery date

- SLA Missed: (Negative frame) number of Orders/SRs that miss a target delivery date

- SLA Risk Overcome: Number of 'high risk' orders that meet an SLA

- Exception Volume: (Negative frame) number of orders/tasks that result in blocking exceptions or avoidable delays

- Customer Satisfaction: (Conceptual) overall rating of experience by customer (e.g., as collected by a follow-up survey)

- ENG: GPON Adoption: Number of GPON-eligible orders that are converted to GPON

- ENG: Added Services: Number of orders for which SRS (site-ready services) were offered

4. MJ figured he needed to focus on the NY, NE, NJ, PA, CP regions (states) as a pilot as he would have the support of Bob to get real time feedback on the project. Bob also suggested using Outside Plant engineering (OSP), Circuit Design Engineering, Circuit Testers, Inter-office Plant engineers (user groups). He would be affecting around 5000 users. SCI suggested to MJ to go with the two prototypes in pilot mode:

- Prototype 1: Climb the mountain Challenge - Close 30000 tasks in 30 days from one Region. Current Volume was 20000.

○ Prototype 2: "Kick the Risk Challenge" - meet 98\% of risky SLAs. (Exhibit - 6) 
5. Periodic Evaluation of games and models - MJ had to understand the positive and negative impact of gamification. He would need to pull out KPI's after implementing gamification. This would be a key indicator for Bob in evaluating if MJ's plan was succeeding in meeting his needs. The KPI's and the gamification algorithm had to be customized per department to make sure the evaluation was done fairly.

6. Technical leads with the project also briefed MJ that the gamification platform would be deployed with existing nSPOG Micro-Frontend Architecture with the presentation layer being defined as a single page application. Component based architecture enabled high reusability of component libraries across ABC applications. MJ was also aware that the majority of data required to implement game mechanics was already being captured by different data-streams in production.

\section{The Recommendation}

After the meeting with SCI and his tech leads MJ now had to make the recommendations and MJ only had a week to present his solution plan to Bob. MJ did a thorough research on organizational behavior stimulants and what all theories could be associated with performance of an employee. These are listed in Exhibit 12.

In considering what to recommend, $\mathrm{MJ}$ analyzed motivational stimulants of employees at workplace to better understand mental map of the engineers. He understood that success of the gamification platform heavily depended on the rapport that developed between engineers and game.

As MJ sketched out his ideas on the whiteboard, he soon realized that he had only 4 choices:

Recommendation 1: Pilot gamification by deploying it to Felicia's organization. With MJ's piloting approach, he would create a generic template for gamification to deploy to different teams. Then learning from how the deployment performed MJ could then deploy it to Maureen's department. Since this recommendation would be a pilot, gamification could easily be turned off. Since Felicia's team was more receptive to change, the early implementation would stand a better chance of succeeding. Dealing with a younger workforce, MJ anticipated the training time would be reduced. Innovative game design would need to be built to engage users. Part of the game mechanics would be to get a budget to reward the better performers. Using a generic template for all teams meant reduced development cost.

The main risk with the choice was that failure of the pilot would likely mean that the whole project would be quashed. If the approach failed with its best user base, what would be the point of continuing? There was also a small risk that gamification might impeded the revenue stream or cause delay for users in getting their job done. The other thing that was on MJ's mind was if Felicia's team would accept the pilot. He needed to ensure users didn't feel pressured or fell micromanaged, as that might leave a negative taste for this user base.

Recommendation 2: Customize the gamification template to match Maureen's team and Felicia's team by working closely with them. This was also a failsafe model where the gamification module could be turned off for a department if needed. He could integrate with the established ABC platform. MJ knew creating these custom gamification templates would be time consuming and he did not have much time. The software quality might be sacrificed for customization.

On the flip side, getting gamification deployed by both the major departments at once was a risk. It could lead to complaints from the user base that could cause the project and idea to be abandoned. MJ would 
also need a budget to create a reward system to reward the best gamers for their performance. Users might push back using legal means or might complain about the perception of micromanagement.

Recommendation 3: Subscription based Games - MJ though that engagement might go a notch higher if users were allowed to choose from a set of available games based on their preferences. MJ thought this approach might familiarize users with the idea of gamification and create user engagement model. Eventually, this model could expand to more serious games (volume of conversion of copper customer to fiber customer). He also noted that users are likely to feel valued as they are not forced on to be part of gamification platform by default.

Recommendation 4: Open-source collaborative Game template theme - MJ thought that success of gamification would not only depend on development of competitive games but also on collaboration of the engineering team with the development team. He thought that if selected supervisors/engineering lead/SPOC could share their idea of Games/Reward strategy with development team, they might also become the flagbearers of the gamification platform to the engineering community. In other words, MJ thought of letting players or selected few coaches design the game with appropriate rewards.

MJ performed a SWOT Analysis, as shown in (Exhibit 11) on the above recommendations.

\section{The Conclusion}

Based on the innovation MJ had already accomplished with Bob on NSPOG MJ knew Bob might be open to a radical concept like gamification. But due to the legal and contractual issues with its union workers he knew there were roadblocks. MJ was ready to meet Bob and potentially help him understand his options and educate him on gamification and its concepts. 


\section{Acknowledgements}

This case study is based upon ABC Corp's gamification platform which is enabler for engineers engagement with new enterprise application nSPOG.

\section{Biographies}

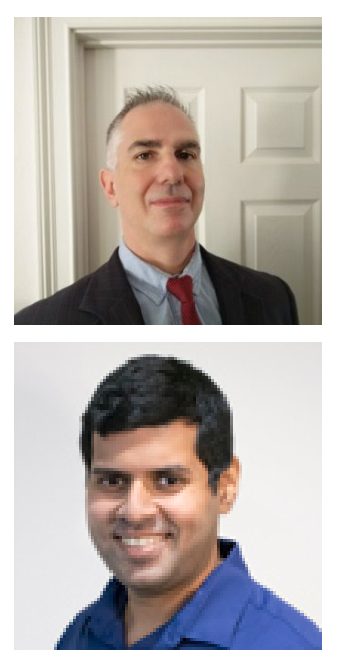

James Farley is a finance professional with an MBA in finance and 20+ years working at various Hedge Funds and Investment Banks. James is working on an MS in Business Analytics at USF to pursue a career in data analytics that utilizes his experience with finance, data and programming. The long-term pursuit is academia.

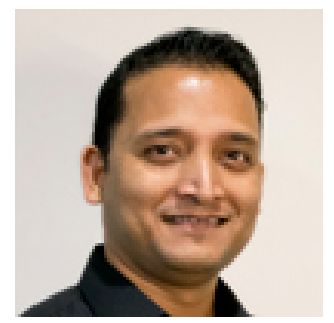

Rishiraj Mukherjee is currently working as Director of Integrations And ERP at Hit Promotional Products. Had Experience in software architect with a demonstrated history of working in the marketing and advertising industry.

Aditya Singh is a Student of MS-BAIS Fall 2018 and currently working as Senior Member of technical staff in ABC Corp Communications. His area of expertise include Software architecture and development.

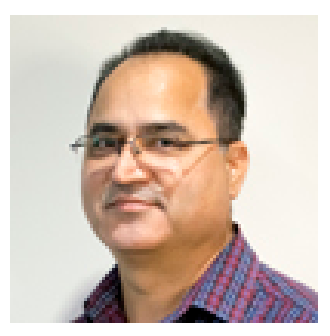

Rajendra Katyal is an information technology professional with experience in software development, database administration, access management, release control, tech refresh, devops, cyber security \& risk management. At present managing code repositories for multiple applications in our group and building automation tools for release management.

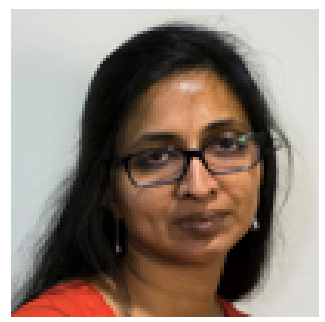

Meena Sundinti is currently working as applications developer at AAA Auto Club Group. She has seven years of professional experience in ETL datawarehouse tools. Pursuing Masters in Executive Business Analytics and Information Systems at USF. 


\section{Exhibit 1: Glimpse of TASK SLA}

This is ABC Corp internal report and data collected against each task. This report provides a snapshot of task and their ageing period. Column $\mathrm{G}$ and $\mathrm{H}$ is matter of concern because SLA for each task agreed - 03 Days.

Column A - Region where task is assigned

Column B - Engineer's workgroup responsible for task completion

Column C - Skillset needed to complete the Task.

Column D - Task Name and Identification

Column E-H - Task Ageing classification

\begin{tabular}{|c|c|c|c|c|c|c|c|c|}
\hline 4 & A & B & C & D & $E$ & $\mathrm{~F}$ & G & $\mathrm{H}$ \\
\hline 1 & Region & Workgroup & Skillset & Task Name & Days 0-1 & Days 2-3 & Days 4-8 & Days 8+ \\
\hline 2 & \multirow[t]{19}{*}{$\mathrm{CP}$} & \multirow[t]{19}{*}{ CPCOCO } & \multirow[t]{2}{*}{ 911_AODCircuitTest_CP } & Complete Circuit Turn-Up & 0 & 0 & 0 & 2 \\
\hline 3 & & & & Verify Installation Readiness & 0 & 0 & 0 & 1 \\
\hline 4 & & & \multirow[t]{5}{*}{ 911_CircuitTest_CP } & Complete Circuit Turn-Up & 6 & 0 & 0 & 15 \\
\hline 5 & & & & Confirm Disconnect & 0 & 0 & 1 & 1 \\
\hline 6 & & & & Verify Central Office Continuity & 0 & 0 & 1 & 7 \\
\hline 7 & & & & Verify Design and Equipment & 0 & 0 & 0 & 52 \\
\hline 8 & & & & Verify Installation Readiness & 0 & 0 & 0 & 1 \\
\hline 9 & & & \multirow[t]{3}{*}{ CarrierAODCircuitTest_CP } & Complete Circuit Turn-Up & 0 & 0 & 0 & 4 \\
\hline 10 & & & & Complete IAD & 0 & 0 & 0 & 9 \\
\hline 11 & & & & Verify Design and Equipment & 0 & 0 & 0 & 3 \\
\hline 12 & & & \multirow[t]{3}{*}{ CarrierCircuitDesign_VA_MD_DC } & Confirm Cancellation & 0 & 0 & 2 & 0 \\
\hline 13 & & & & Design Circuit & 2 & 65 & 20 & 59 \\
\hline 14 & & & & Modify Circuit Design & 0 & 0 & 0 & 14 \\
\hline 15 & & & \multirow[t]{5}{*}{ CarrierCircuitTest_CP } & Complete Circuit Turn-Up & 0 & 0 & 0 & 44 \\
\hline 16 & & & & Complete IAD & 0 & 0 & 0 & 22 \\
\hline 17 & & & & Confirm Disconnect & 0 & 0 & 0 & 55 \\
\hline 18 & & & & Verify Design and Equipment & 0 & 0 & 0 & 3 \\
\hline 19 & & & & Verify Installation Readiness & 0 & 0 & 0 & 33 \\
\hline & & & 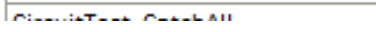 & م & $n$ & $n$ & $n$ & \\
\hline
\end{tabular}




\section{Exhibit 2: QQPLOT diagram of Average time to work on task}

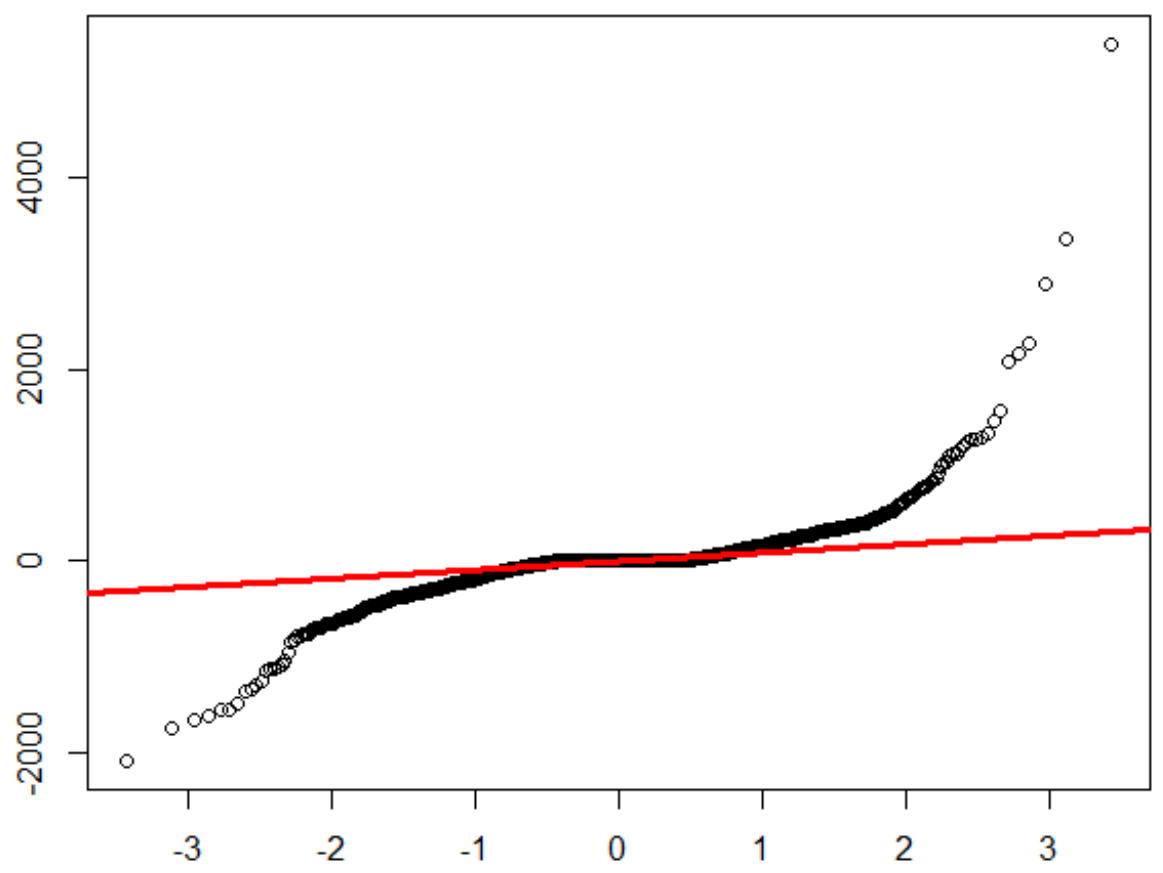

\begin{tabular}{|c|c|c|c|}
\hline 4 & A & B & $\mathrm{C}$ \\
\hline 1 & Task Name & Product & Avg Handling Time \\
\hline 2 & AAC Construction Complete & & 20 \\
\hline 3 & ADDRESS-VAL & DS1/SES & $850: 50: 02$ \\
\hline 4 & ASR-Assignment & 1.984MBS & $3867: 21: 27$ \\
\hline 5 & ASR-Assignment & 10-E1 & $1251: 33: 57$ \\
\hline 6 & ASR-Assignment & 100-DS3 & $1081: 49: 13$ \\
\hline 7 & ASR-Assignment & 100-DS3B & $75: 05: 54$ \\
\hline 8 & ASR-Assignment & 100-E1 & $435: 15: 10$ \\
\hline 9 & ASR-Assignment & 100-E1B & $460: 53: 31$ \\
\hline 10 & ASR-Assignment & 100-E1T & $74: 54: 21$ \\
\hline 11 & ASR-Assignment & 100G-B & $0: 00: 00$ \\
\hline 12 & ASR-Assignment & 10OGLANP & 11:04:03 \\
\hline 13 & ASR-Assignment & 100GLMPL & $868: 35: 06$ \\
\hline 14 & ASR-Assignment & 100GOTU4 & $0: 23: 34$ \\
\hline 15 & ASR-Assignment & 10OM-ETH & $722: 15: 44$ \\
\hline 16 & ASR-Assignment & 1OG-ETH & $854: 32: 39$ \\
\hline 17 & ASR-Assignment & 1OG-LANP & $1536: 20: 52$ \\
\hline 18 & ASR-Assignment & 1OGL-MPL & 490:12:15 \\
\hline 19 & ASR-Assignment & 10GLNGDL & 588:52:29 \\
\hline 20 & ASR-Assignment & 10GTRMPL & $856: 15: 29$ \\
\hline 21 & ASR-Assignment & 10M-ETH & $831: 23: 44$ \\
\hline 22 & ASR-Assignment & 1G-DS3 & $228: 24: 37$ \\
\hline 23 & ASR-Assignment & 1G-ETH & $811: 37: 29$ \\
\hline
\end{tabular}


MUMA CASE REVIEW

. tactor (datascustomer. region) Europe

- factor (data\$customer. region) GA

. factor (data\$customer. region) IF

. factor (data\$customer. region) In-Franchise

. factor (data\$customer. region) Indianapolis - IN

. factor (data\$customer. region)LA

- factor (data\$customer. region) LatAm

factor (data\$customer. region)MA

- factor (data\$customer.region)MA_RI

. factor (data\$customer.region)MD

. factor (data\$customer. region)MEA

. factor (data\$customer. region)MI

. factor (data\$customer. region)MN

. factor (data\$customer. region)NA

. factor (data\$customer. region) NC

. factor (data\$customer. region) NE

. factor (data\$customer. region)NJ

.factor (data\$customer. region) NORTH

. factor (data\$customer. region) NY

. factor (data\$customer. region) NY Capital

. factor (data\$customer. region) NYC

. factor (data\$customer. region)NYS

. factor (data\$customer. region) $\mathrm{OH}$

- factor (data\$customer. region)oof

. factor (data\$customer. region)OR

. factor (data\$customer. region)PA

.factor (data\$customer.region)PA-DE

. factor (data\$customer. region) PA/DE

. factor (data\$customer. region)Phoenix - AZ

- factor (data\$customer. region)Potomac

-factor (data\$customer. region)RI

. factor (data\$customer. region)s2

. factor (data\$customer.region)TN

. factor (data\$customer. region)TX

. factor (data\$customer. region) unspecified

. factor (data\$customer. region) Us

- factor (dat a \$customer. region) USA

. factor (data\$customer. region) UT

. factor (data\$customer. region)VA
8. 5131

$-10.1869$

$-9.6019$

$-8.8535$

$-6.0202$

$-10.1869$

$-5.9610$

$-9.9202$

$-4.1011$

215.3131

$-5.7910$

$-10.1869$

$-10.1869$

$-10.1869$

$-9.9011$

$-10.1869$

$-9.9191$

$-9.7264$

$-10.1869$

$-9.6660$

$-4.1869$

23.1465

107.3131

$-9.4369$

$-9.6214$

$-10.1869$

$-9.7253$

96.8131

$-8.9369$

$-10.1869$

94.8131

$-8.1869$

$-10.1869$

$-9.1869$

$-9.1869$

193.8131

$-9.7319$

$-10.1869$

$-10.1869$

$-5.5134$
$0.684312 .440<2 \mathrm{e}-16 * * *$

$5.4952-1.854 \quad 0.063775$.

$0.7003-13.711<2 \mathrm{e}-16 * * *$

$\begin{array}{llll}2.6214 & -3.377 & 0.000732 & * *\end{array}$

$\begin{array}{llll}3.1944 & -1.885 & 0.059485\end{array}$

$\begin{array}{llll}7.7580 & -1.313 & 0.189160\end{array}$

$1.4637-4.073 \quad 4.65 \mathrm{e}-05 * * *$

$2.0509-4.8371 .32 \mathrm{e}-06 * * *$

$\begin{array}{llll}1.3861 & -2.959 & 0.003090 * *\end{array}$

$5.495239 .182<20-16 * * *$

$\begin{array}{llll}5.4952 & 39.182 & <2 \mathrm{e}-16 & * * * \\ 1.2071 & -4.797 & 1.61 \mathrm{e}-06 & * * *\end{array}$

$7.7580-1.3130 .189160$

$\begin{array}{llll}3.8990 & -2.613 & 0.008986\end{array}$ **

$5.4952-1.8540 .063775$.

$2.9624-3.3420 .000832 * * *$

$\begin{array}{llll}3.4933 & -2.916 & 0.003546 * *\end{array}$

$0.4759-20.842<2 \mathrm{e}-16$ ***

$0.4781-20.345<2 \mathrm{e}-16 * *$

$\begin{array}{llll}5.4952 & -1.854 & 0.063775\end{array}$.

$0.4698-20.575<2 \mathrm{e}-16 * * *$

$\begin{array}{llll}3.8990 & -1.074 & 0.282904\end{array}$

$3.1944 \quad 7.2464 .35 \mathrm{e}-13 * * *$

$5.495219 .529<2 \mathrm{e}-16$ **

$3.8990-2.4200 .015510$ *

$0.7514-12.805<2 \mathrm{e}-16 * * *$

$4.4945-2.267 \quad 0.023423$ *

$0.4745-20.494<2 \mathrm{e}-16 * * *$

$5.495217 .618<2 \mathrm{e}-16 * * *$

$3.8990-2.292 \quad 0.021904$ *

$2.9624-3.4390 .000585 * * *$

$5.495217 .254<2 \mathrm{e}-16 * * *$

$1.7907-4.5724 .84 \mathrm{e}-06 * * *$

$2.9624-3.4390 .000585$ **

$\begin{array}{llll}5.4952 & -1.672 & 0.094568 \text {. }\end{array}$

$\begin{array}{llll}4.4945 & -2.044 & 0.040955 *\end{array}$

$7.758024 .982<2 \mathrm{e}-16 * * *$

$0.4581-21.242<20-16$ ***

$\begin{array}{llll}7.7580 & -1.313 & 0.189160\end{array}$

$\begin{array}{lll}7.7580 & -1.313 & 0.189160\end{array}$

$1.1965-4.608 \quad 4.08 \mathrm{e}-06$ *** 


\section{Exhibit 3: Manual Touches performed on each task}

This report briefs manual touches (when engineer change something on the task) by an engineer on a task to complete. Every touch counts towards expense and add time elapsed on task completion.

Column A - Task Name and Identification

Column B - Unique SO

Column C - Product association.

Column D - Geographical Identification

Column $\mathrm{H}$ - Manual touch on the task by engineers.

\begin{tabular}{|c|c|c|c|c|c|c|c|c|}
\hline 4 & $\mathrm{~A}$ & B & C & D & $E$ & $\mathrm{~F}$ & G & $\mathrm{H}$ \\
\hline 1 & Task Name & Service Order Number & Product & $\begin{array}{l}\text { Customer } \\
\text { Region }\end{array}$ & CLO & CAC & $\begin{array}{l}\text { TFAS Contact } \\
\text { ID }\end{array}$ & Touches \\
\hline 2 & AAC Construction Complete & & & & & & & 1 \\
\hline 3 & ADDRESS-VAL & C2FB16136 & DS1/SES & S2 & & & & 1 \\
\hline 4 & ADDRESS-VAL & C2FB17191 & DS1/SES & S2 & & & & 1 \\
\hline 5 & ASR-Assignment & NA & 100M-ETH & Europe & & & & 1 \\
\hline 6 & ASR-Assignment & NA & 1G-ETH & AsiaPac & & & & 2 \\
\hline 7 & ASR-Assignment & NA & 1G-ETH & Europe & & & & 1 \\
\hline 8 & ASR-Assignment & NA & $8 \mathrm{M}$ & AsiaPac & & & & 1 \\
\hline 9 & ASR-Assignment & NA & E-1 & Europe & & & & 1 \\
\hline 10 & ASR-Assignment & NA & ETHER 8 & AsiaPac & & & & 2 \\
\hline 11 & ASR-Assignment & NA & ETHR-ACC & AsiaPac & & & & 2 \\
\hline 12 & ASR-Assignment & NA & INT-DSL & AsiaPac & & & & 4 \\
\hline 13 & ASR-Assignment & NA & NON-CORE & AsiaPac & & & & 1 \\
\hline 14 & ASR-Assignment & NA & PETHDS3 & Europe & & & & 1 \\
\hline 15 & ASR-Assignment & NA & PETHE-1 & Europe & & & & 1 \\
\hline 16 & ASR-Assignment & NA & SDSL & AsiaPac & & & & 3 \\
\hline 17 & ASR-Assignment & & 10-E1 & Europe & & & & 125 \\
\hline 18 & ASR-Assignment & & 100-DS3 & Europe & & & & 236 \\
\hline 19 & ASR-Assignment & & 100-DS3B & America & & & & 2 \\
\hline 20 & ASR-Assignment & & 100-E1 & Europe & & & & 24 \\
\hline 21 & ASR-Assignment & & 100-E1B & America & & & & 15 \\
\hline 22 & ASR-Assignment & & 100-E1B & Europe & & & & 8 \\
\hline 23 & ASR-Assignment & & 100-E1T & AsiaPac & & & & 1 \\
\hline 24 & ASR-Assignment & & 100G-B & Europe & & & & 1 \\
\hline 25 & ASR-Assignment & & 100GLANP & America & & & & 6 \\
\hline 26 & ASR-Assignment & & 100GLMPL & Europe & & & & 1 \\
\hline
\end{tabular}




\section{Exhibit 4: Performance and Work velocity report}

This report briefs on average time elapsed by engineer on a task in a given duration. Every task completion and time elapsed is measured against SLA assigned to each task. This report gives a brief on how many task completions were beyond SLA and this provides a key metrics to gamification platform for efficiency measurement.

Column C - Task Name and Identification

Column $\mathrm{O}-$ Average work time on task by engineer.

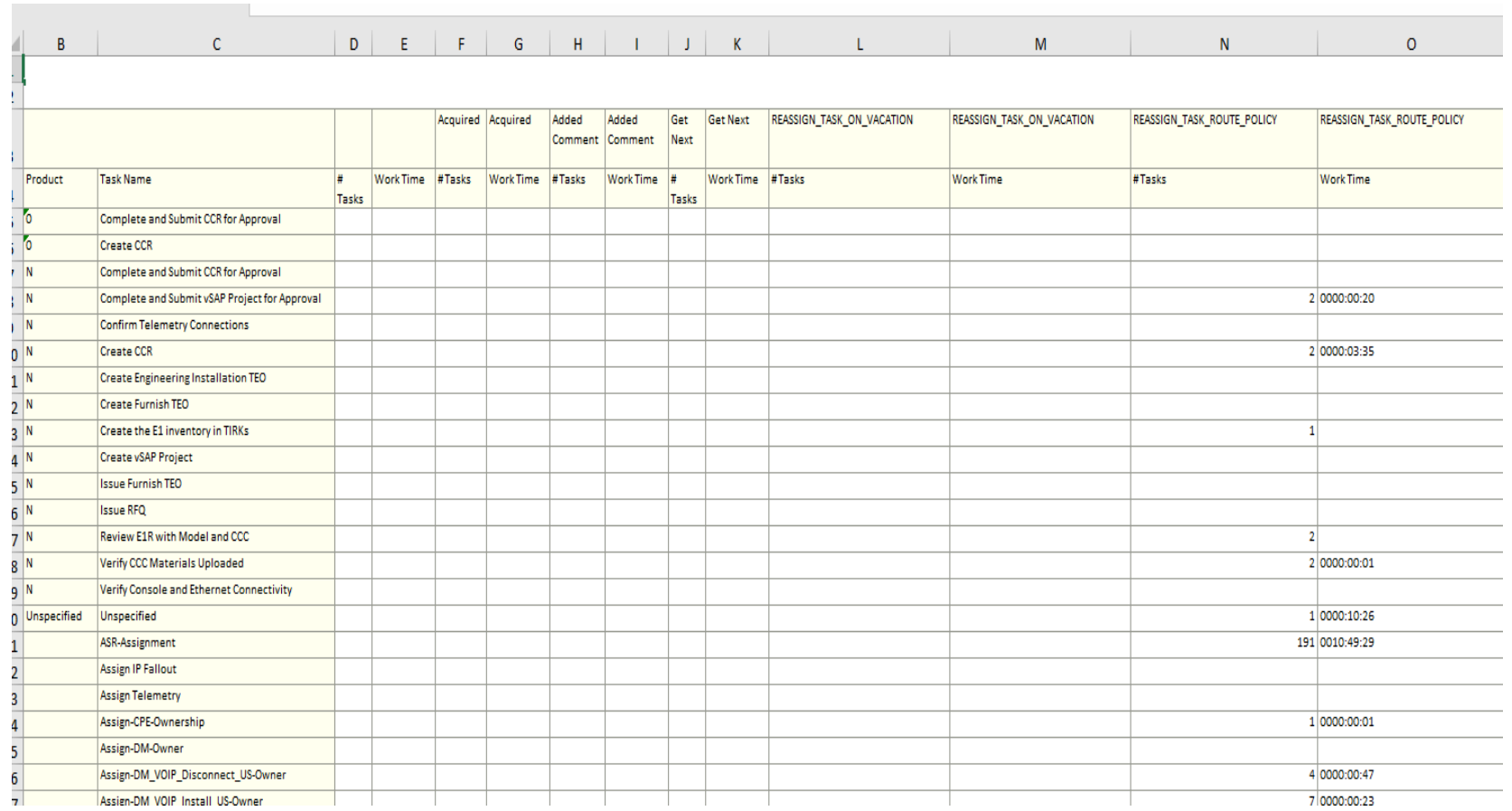




\section{Exhibit 5: Task Dashboard}

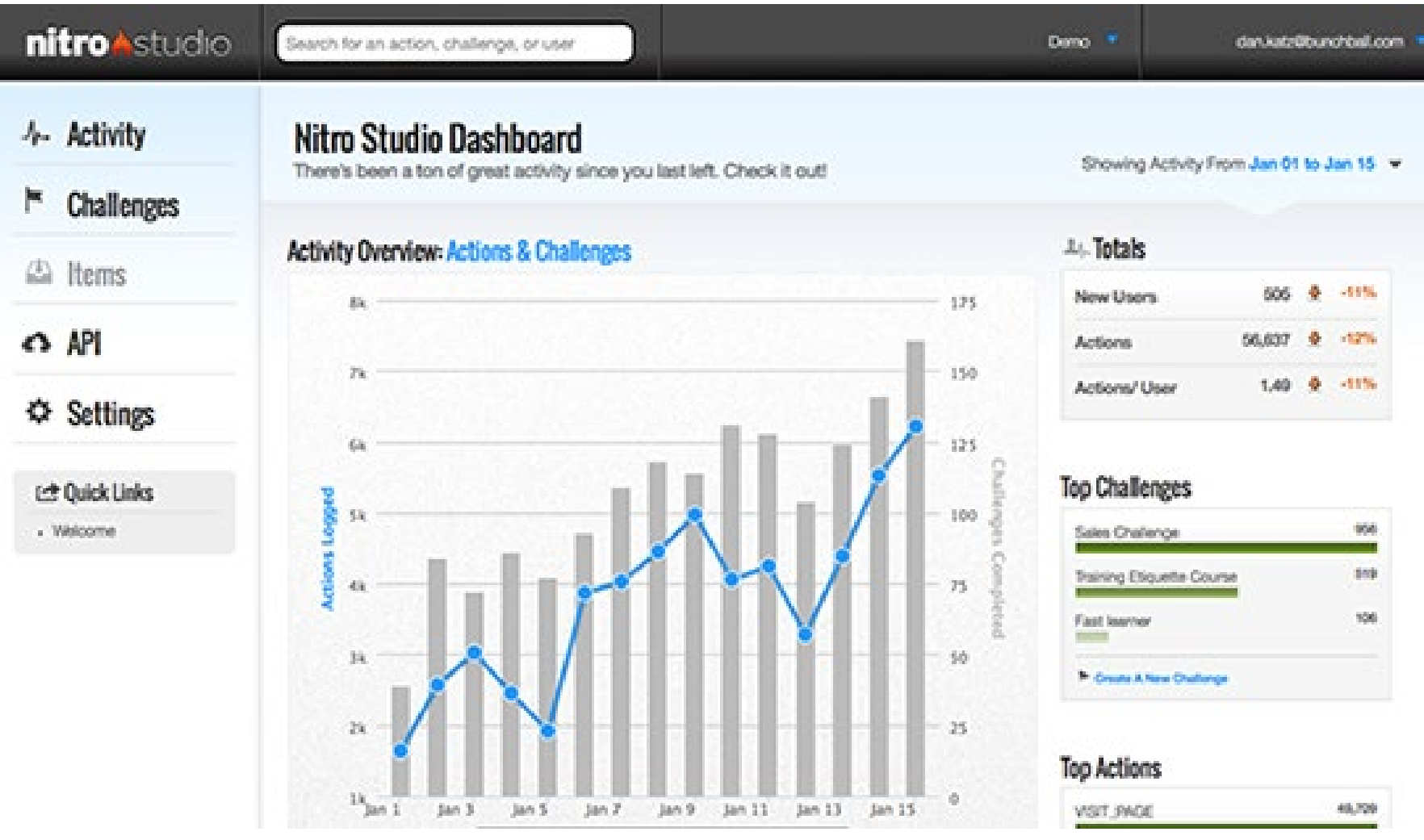




\section{Exhibit 6: Gamification Prototype -4Q Risky SLA Team Challenge}

Prototype -1 Risky SLA team challenge as perceived by SCI after their initial round of interview with engineers.

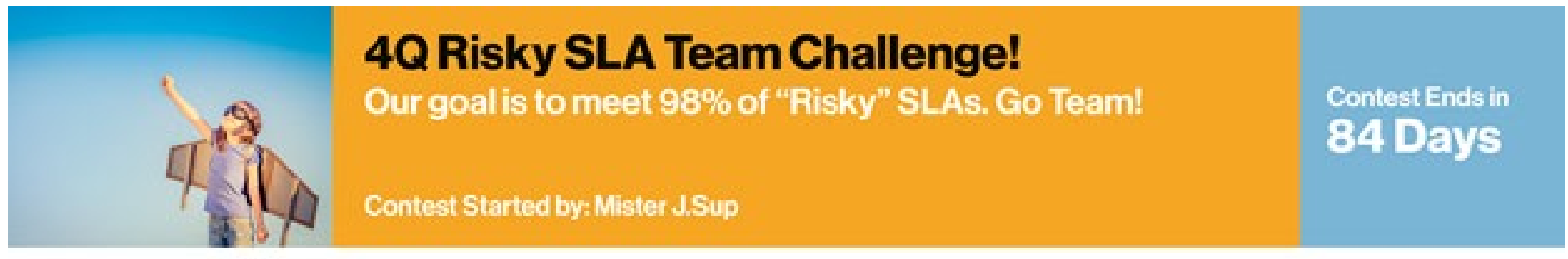

Team Members

\begin{tabular}{|c|c|c|}
\hline & Goals & Rank \\
\hline L. Doberino & 121 & Master \\
\hline S. Merona & 80 & Master \\
\hline R.Luca & $n$ & Journeyman \\
\hline A. Shoh & 52 & Acorentice \\
\hline
\end{tabular}

Team Progress

SLA Met/Missed $334 / 34$

Current Average

91\%

Progress to Goal

$-7 \%$

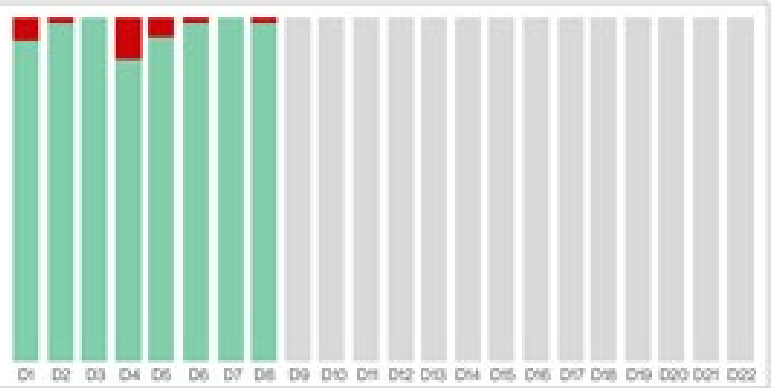




\section{Exhibit 8: Enterprise Gamification Architecture and Platform}

Game Masters - Game Template designers and acts as referee throughout the game duration.

Players - Outside Plant Engineers, Inter-office planners, Circuit designers and testers group.

Other Users - RF engineers, Tier-1 support team and Project Management Group.

Gamification platform connects with existing nSPOG Architecture via Single-Sign On authorization. Core gamification engine comprise Interaction History, Games History, Game Algorithm, Recommender engine based on past learning and gamification API. AI Bots provide real time analysis to user on how to accomplish task faster by highlighting risk.

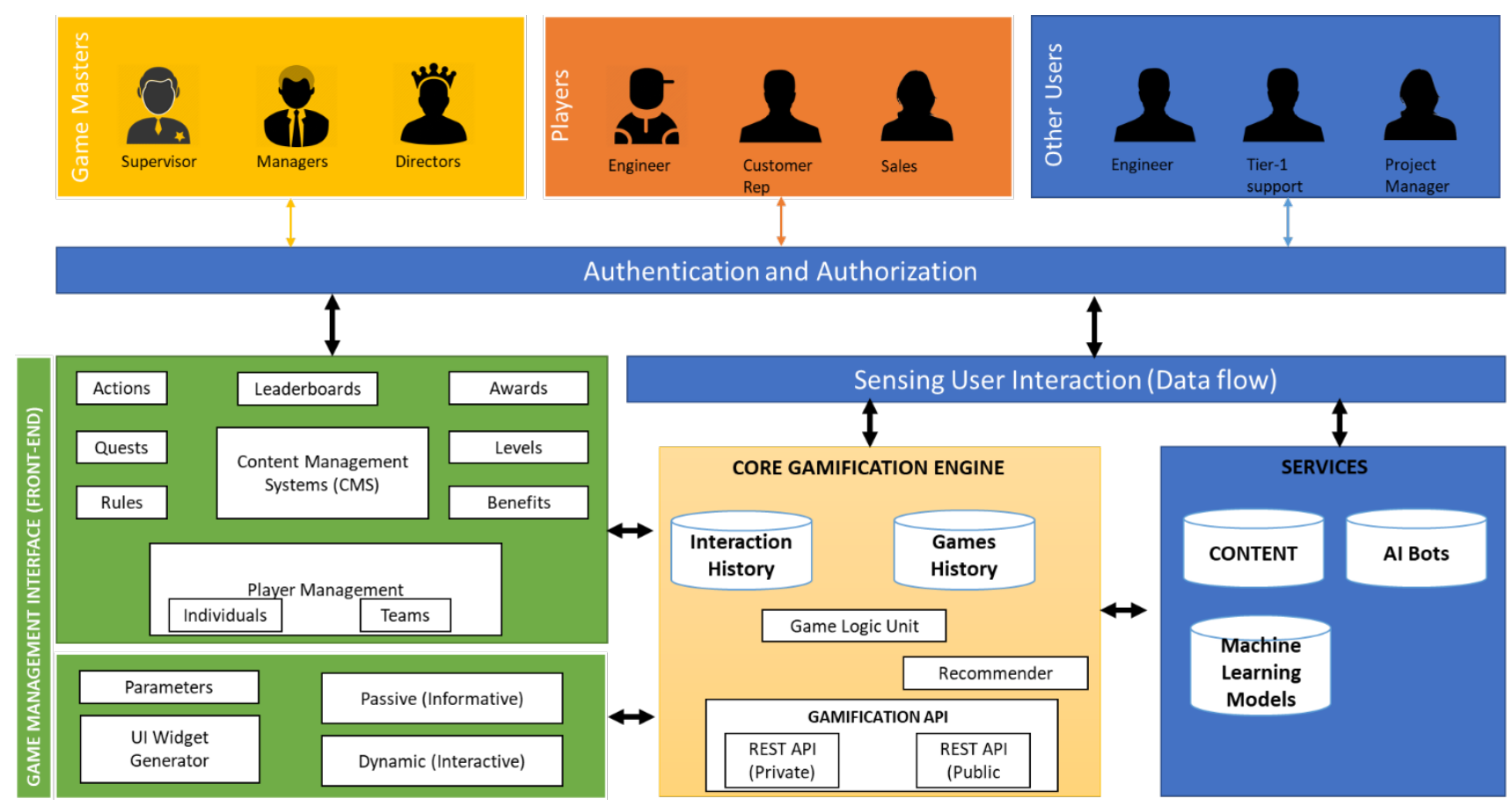




\section{Exhibit 9: Enterprise Gamification Growth numbers}

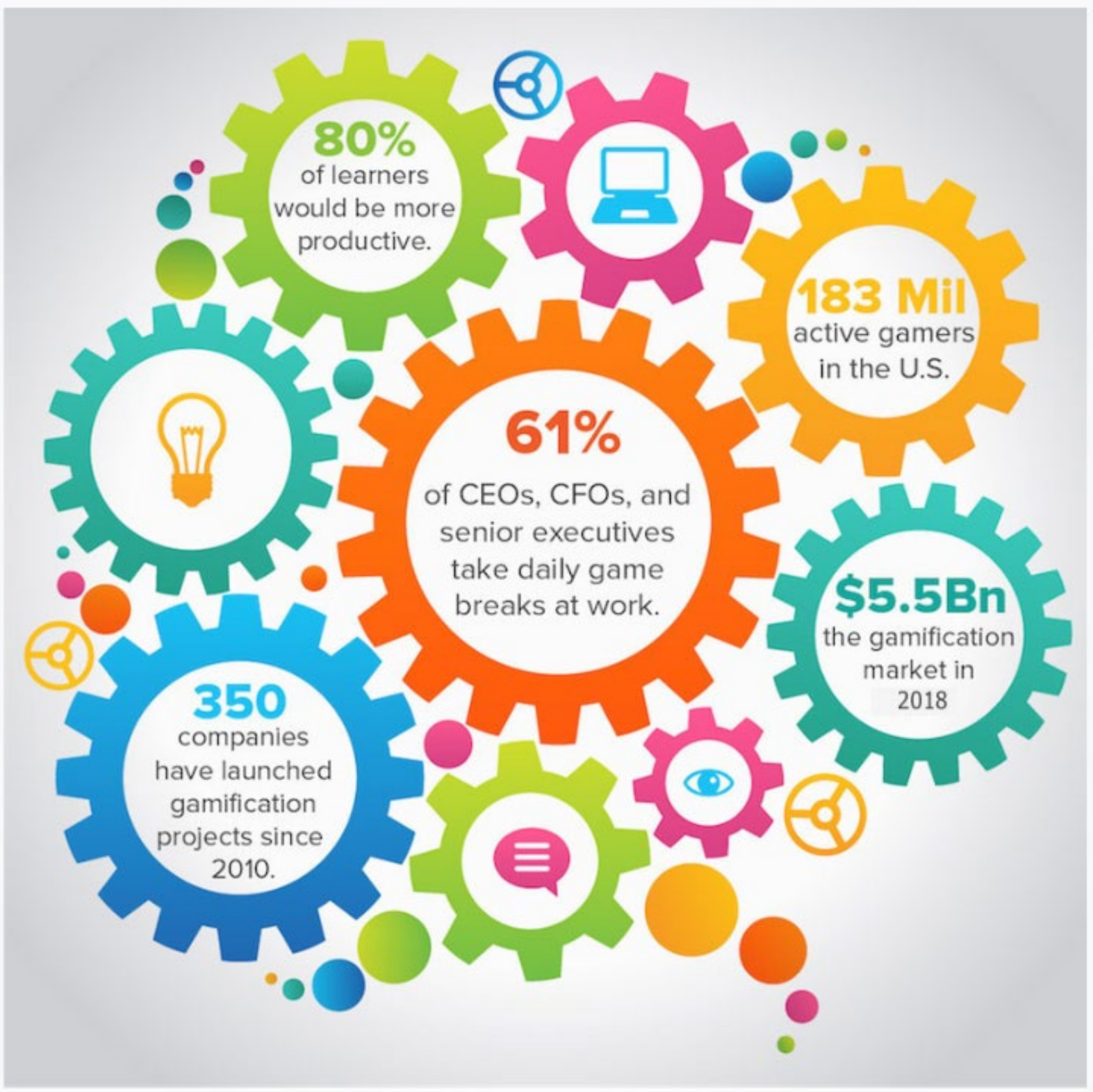




\section{Exhibit 10: Gamification - Need of the Hour}

\section{Company Culture}

Only $28 \%$ of top HR executives believe they understand their culture well, while only $19 \%$ believe they have the "right culture." (Deloitte.)

Only $26 \%$ of employers offer maternity leave coverage beyond short-term disability leave. (Fast Company)

$94 \%$ of executives and $88 \%$ of employees believe a distinct workplace culture is important to business success. (Deloitte.)

\section{HR Leadership}

$83 \%$ of HR leaders report they are influential in shaping decisions. (CEB)

$70 \%$ of heads of HR are spending more time participating in business projects in a leadership capacity. (CEB)

Forging strategic partnerships with external organizations was a top focus of heads of HR. (CEB)

\section{Employee Engagement}

$70 \%$ of U.S. workers are not engaged at work (Forbes)

$70 \%$ of business transformation efforts fail due to lack of engagement. (Forbes)

$90 \%$ of leaders think an engagement strategy is important for business success, but only $25 \%$ of them have a strategy. (Forbes)

Companies with engaged employees have $2.5 x$ higher revenues than companies with low engagement. (Daily Infographic)

\section{Growth of Gamification}

Gamification improves the work experience of $91 \%$ of Employees, and increases productivity across U.S. companies. (Badgeville)

$70 \%$ of Forbes Global 2000 companies are planning to use gamification to boost engagement, retention, and revenues. (Forbes)

Almost $80 \%$ of learners say that they would be more productive if their university/institution or work was more game-like. (Digital Chalk)

The worldwide gamification market will grow from $\$ 242$ million in 2012 to $\$ 22.9$ Billion by 2022. (P\&S Market Research) 


\section{Exhibit 11: SWOT ANALYSIS}

1. Deploy by pilot phase and work with Felicia's team for deployment if that works, then deploy to Maureen's team.

\begin{tabular}{|l|}
\hline Recommendation 1 \\
Pilot Model - \\
Launch Gamification \\
platform for Genia's \\
organization and \\
address the learning \\
to expand it to \\
Maureen's \\
organization. \\
\end{tabular}

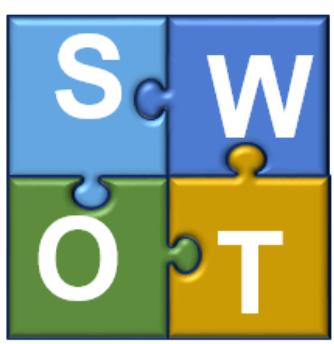

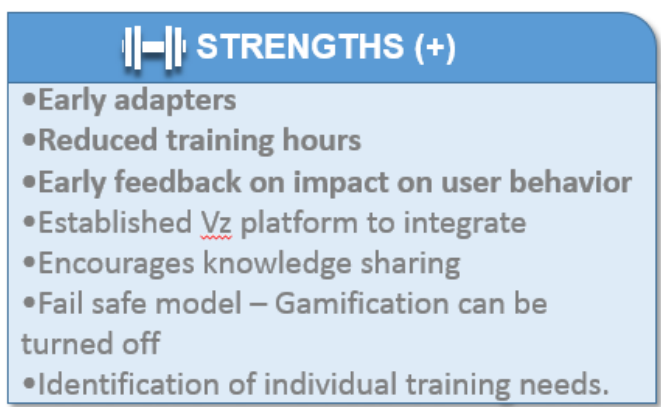

\section{渵 OPPORTUNITIES (+)}

-Innovative games design to push for user engagement.

- Game mechanics to encourage user to support new product launches.

- Rewards as per performance

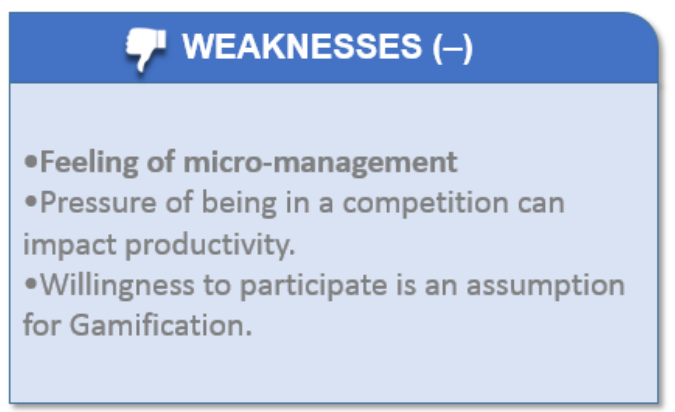

\section{THREATS (-)}

- Negative perception among user community if not implemented properly.

- Legal compliances (international regulation)

-Verizon separation program - SME leaving

organization. 
2. Custom build gamification templates for Maureen and Felicia's team

\begin{tabular}{|l|}
\hline Recommendation 2 \\
\hline Customize \\
Gamification as per \\
VP Organization - \\
Genia Org - \\
Individual + Team \\
based Gamification \\
template \\
Maureen Org - Team \\
based Gamification \\
template \\
\hline
\end{tabular}

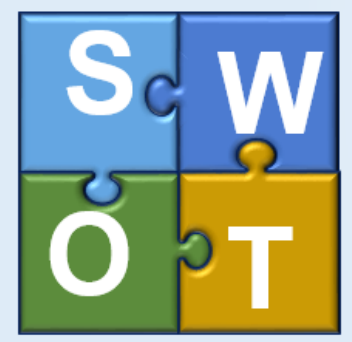

\section{WEAKNESSES $(-)$}

- Limited pushback from users.

-Win-win situation for Maureen and Genia

- Established Vz platform to integrate

- Encourages knowledge sharing

- Fail safe model - Gamification can be

turned off

\section{OPPORTUNITIES (+)}

- Innovative games design to push for user and team engagement.

- Game mechanics to encourage user to

support new product launches.

- Rewards as per performance 
3. Subscription Based implementation- Allow engineers to select the game they want to participate during a period.

\begin{tabular}{|l|}
\hline Recommendation 3 \\
Subscription Based \\
implementation- \\
Allow engineers to \\
select the game they \\
want to participate \\
during a period.
\end{tabular}

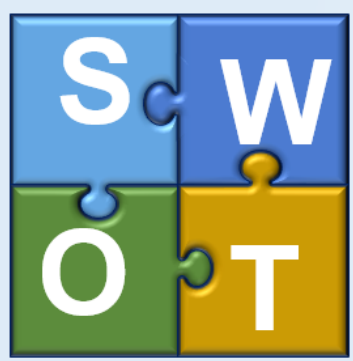

\section{U-|| STRENGTHS (+)}

- Minimal or no pushback from engineers.

- Early insight into engineers mental map

- Early success in gamification

implementation and adoption

- Scaled up model.

\section{OPPORTUNITIES (+)}

- Train them on new application- nSPOG

- Games can be enhanced based on early success model and can increase nSPOG adoption.

\section{WEAKNESSES (-)}

-Serious games implementation can become a challenge.

- Can kill innovation towards new games.

- Engineers can become complacent after sometime or loose interest in the game.

\section{THREATS (-)}

- Participation from engineers can be challenging as it is not forced one. -Feeling of being micro-managed. - Negative perception among user community if not implemented properly. 
4. Work with Engineering community to design games and rewards - Allow engineering community to work with IT to design games and rewards.

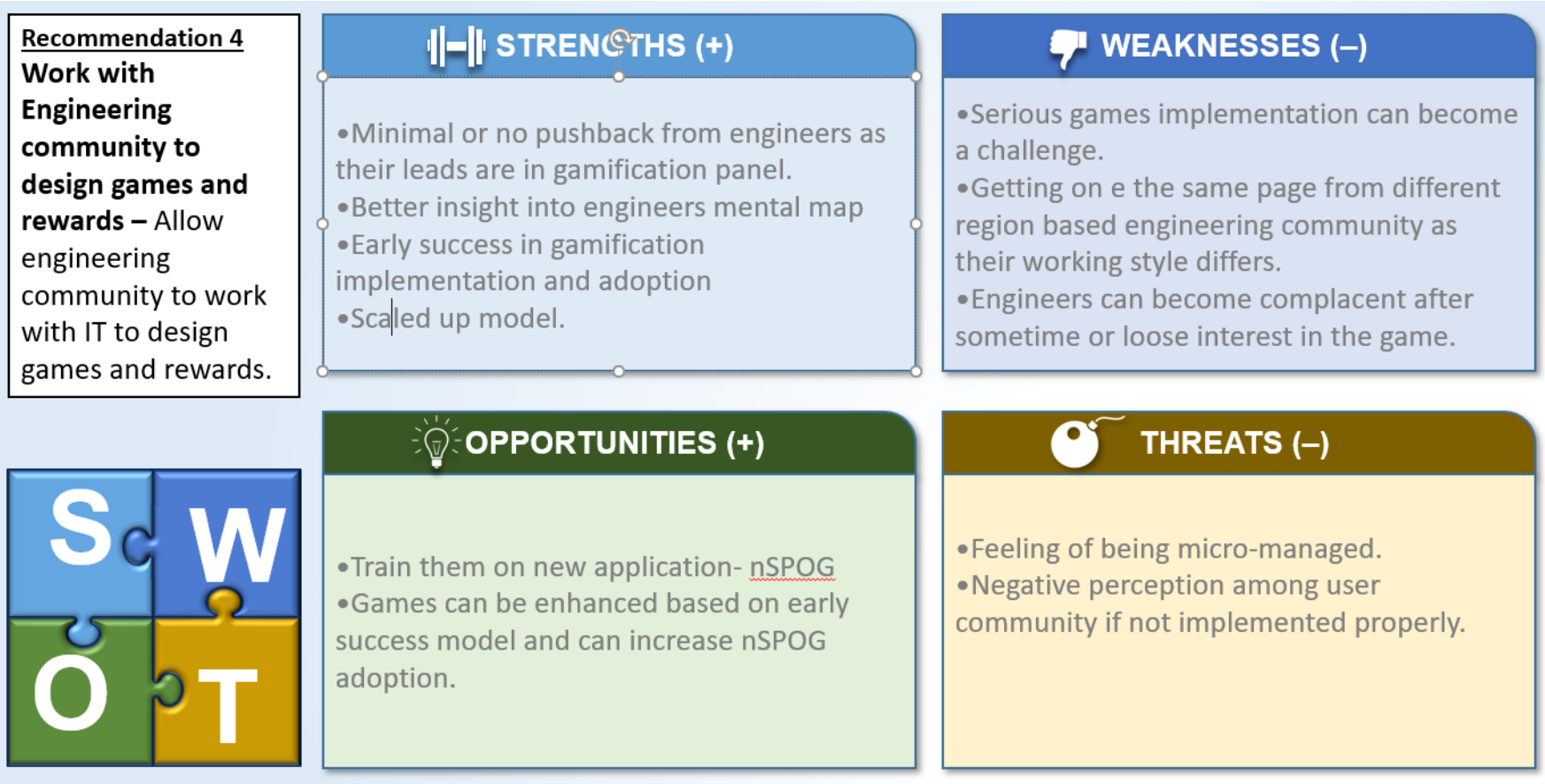




\section{Exhibit 12: Organizational Behavioral Theory and Expectancy Theory}

1. Self-Determination Theory: People prefer to feel they have control over their actions, so anything that makes a previously enjoyed task feel more like an obligation than a freely chosen activity will undermine motivation.

Major implications for work rewards

- Intrinsic and Extrinsic rewards are not independent

- Extrinsic rewards may decrease intrinsic rewards

- Goal setting is more effective in improving motivation

- Verbal rewards increase intrinsic motivation, tangible rewards reduce it

2. Locke's Goal-Setting Theory: Specific and difficult goals, with self-generated feedback, lead to higher performance.

Difficult Goals:

- Focus and Direct attention

- Energize the person to work harder

- Difficulty increases persistence

- $\quad$ Force people to be more effective and efficient.

Relationship between goals and performance depends on:

- Goal commitment (the more public the better)

- Task Characteristics (simple, well-learned)

- Culture

\section{Management by Objectives (MBO)}

- $\mathrm{MBO}$ is a systematic way to utilize goal-setting.

- Goals must be:

- Tangible

- Verifiable

- Measurable

- Corporate goals are broken down into smaller, more specific goals at each level of organization.

4. Self-Efficacy Theory/Social Cognitive Theory or Social Learning Theory: An individual's belief that he or she is capable of performing a task.

Higher efficacy is related to:

- Greater confidence

- Greater persistence in the face of difficulties

- Better response to negative feedback

- Self-efficacy complements goal setting theory 


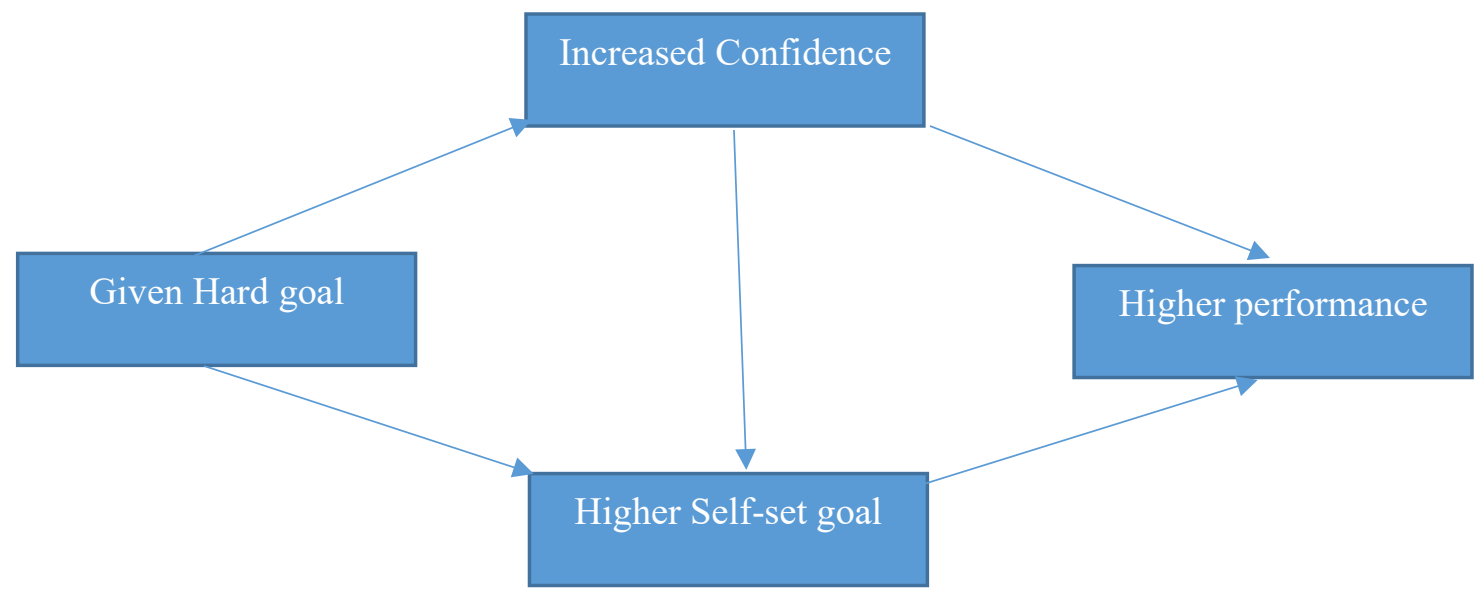

\section{Increasing Self-Efficacy}

Enacting Mastery

- Most important source of efficacy

- Gaining relevant experience with task or job

- Practice makes perfect

Vicarious Modeling

- Increasing confidence by watching others perform the task

- Most effective when observer sees the model to be similar to him or herself

$\underline{\text { Verbal Persuasion }}$

- Motivation through verbal conviction

- Pygmalion and Galatea effects - self-fulfilling prophecies

$\underline{\text { Arousal }}$

- Getting "Psyched up" - emotionally aroused - to complete task

- Can hurt performance if emotion is not a component of the task. 


\section{Equity Theory}

\section{Equity Theory}

Individuals compare their job inputs and outcomes with those of others and then respond to eliminate any inequities.

\begin{tabular}{|l|}
\hline Referent \\
Comparisons: \\
Self-inside \\
Self-outside \\
Other-inside \\
Other-outside \\
\hline
\end{tabular}

Choices for dealing with inequity:
1. Change inputs (slack off)
2. Change outcomes (increase output)
3. Distort/change perceptions of self
4. Distort/change perceptions of others
5. Choose a different referent person
6. Leave the field (quit the job)

Propositions relating to inequitable pay:

1. Overrewarded hourly employees produce more than equitably rewarded employees.

2. Overrewarded piece-work employees produce less, but do higher quality piece work.

3. Underrewarded hourly employees produce lower quality work.

4. Underrewarded employees produce larger quantities of lower-quality piece work than equitably rewarded employees. 


\section{Expectancy Theory}

1 Effort-performance relationship

2 Performance-reward relationship

3 Rewards-personal goals relationship

- All three links between the boxes must be intact or motivation will not occur. Thus,

- Individuals must feel that if they try, they can perform

\section{$+$}

- If they perform, they will be rewarded

\section{$+$}

$\circ$ When they are rewarded, the reward will be something they care about. 